\title{
O PRODUTIVISMO ACADÊMICO COMO EXPRESSÃO DA PRECARIZAÇÃO DO TRABALHO DOCENTE
} PRECARIEDAD DEL TRABAJO DOCENTE

Fábio Mansano de Mello Doutorando do programa de Pós-Graduação em Memória, Linguagem e Sociedade - UESB. fmmello@yahoo.com.br

Ana Elizabeth Santos Alves Docente do programa de Pós-Graduação em Memória, Linguagem e Sociedade - UESB. ana_alves183@hotmail.com

\begin{abstract}
Resumo
O presente artigo tem por escopo apontar os limites da qualificação do trabalho docente, que está cada vez mais precarizado por meio da intensificação, rotinização e do controle ao qual o mesmo é submetido pelo metabolismo capitalista. Num primeiro momento refletimos sobre os conceitos de desqualificação e precarização do trabalho, passando pela ideia da proletarização docente; em seguida, demonstramos como o produtivismo acadêmico é uma expressão concreta da sanha capitalista em potencializar o lucro e consolidar a educação superior como uma rentável mercadoria.
\end{abstract}

Palavras-chave: Produtivismo acadêmico. Qualificação do trabalho. Trabalho docente.

\section{Resumen}

El presente artículo tiene como objetivo señalar los límites de la calificación del trabajo docente, que es cada vez más precario por la intensificación, la rutinización y control al que está sometido por el metabolismo capitalista. Al principio reflexiona sobre los conceptos de descalificación y precariedad del trabajo, a través de la idea de proletarización docente; en seguida, demostramos cómo el productivismo académico es una expresión concreta de potenciar la rentabilidad y consolidar la educación superior como una mercancía rentable. 
Palabras clave: Productivismo académico. Calificación del trabajo. Trabajo docente.

\section{Introdução}

O processo de reestruturação produtiva, ocorrido no final do século XX no âmbito da produção e do trabalho, produziu impactos no campo educacional, por meio da implementação de legislações, organização de currículos e transformações na dinâmica do trabalho docente. Os padrões flexíveis do novo modelo de acumulação do capital fundamentaram mudanças institucionais e organizacionais nas relações de produção e no processo de trabalho, de modo a construir não apenas uma nova subjetividade operária, mas um novo disciplinamento da força de trabalho. No caso dos docentes do ensino superior privado, entendemos que a ideologia da eficiência e da empregabilidade utilizada pelo capital nas instituições de ensino superior (IES) é mais forte do que as faces da precarização do trabalho. Em outras palavras, os professores naturalizam a desqualificação profissional ao qual estão submetidos por aderirem às imposições do mercado e à lógica do capital, e assim, cada vez mais perdem o controle sobre o processo de trabalho.

O objetivo central deste artigo é apontar os limites da qualificação do trabalho docente, que está cada vez mais precarizado por meio da intensificação, rotinização e do próprio controle ao qual o mesmo é submetido pelo metabolismo capitalista.

O processo de flexibilização do trabalho docente demanda transformações no campo da educação e afeta diretamente o ensino superior privado. Um dos elementos centrais desse debate é a exigência de formação de profissionais, segundo um novo perfil de competências e habilidades com possibilidades de inserção no mercado de trabalho, redundando numa massificação do ensino. Bruno (2011, p. 554) aponta que embora o mercado de trabalho tenha exigido cada vez mais um aumento da escolaridade, "essa produção (...) trata-se apenas de garantir o aprendizado de conhecimento meramente instrumental e as competências trabalhadas são de caráter adaptativo às exigências do sistema”. Esse pressuposto incide sobre o trabalho docente que nesse momento é exigido um novo perfil profissional, baseado em novas competências que vão além do mero processo de ensino-aprendizagem, consolidado nas instâncias formativas. Para que essa nova exigência se estabeleça, necessita-se de "um trabalhador vulnerável quanto à ocupação que executa, mutante quanto ao trabalho que 
desenvolve, afável no que se refere à disciplina no ambiente produtivo e tolerante no que tange às relações de contrato e salário" (CAMARGO, 2012, p. 94).

Assim, nas seções que seguem, inicialmente apresentamos algumas discussões sobre os conceitos de desqualificação e precarização do trabalho, passando pela ideia da proletarização docente; em seguida, demonstramos como o produtivismo acadêmico é uma expressão concreta da sanha capitalista em potencializar o lucro e consolidar a educação superior como uma rentável mercadoria.

\section{A desqualificação profissional e trabalho docente}

As IES privadas incorporam o modelo flexível e o professor assiste a precarização crescente do seu trabalho, com relações de contrato trabalhista autônomas, temporárias ou informais. É bem verdade que esse profissional não goza de estabilidade empregatícia como um docente do ensino público, no entanto, a volatilidade e a alta rotatividade do trabalho, aliada à política salarial cada vez é mais achatada e compõe o cenário de sua ocupação. $\mathrm{O}$ trabalhador docente é pressionado não somente pela sociedade no que tange à sua formação, mas também no local de trabalho no qual é exigido uma máxima produtividade e adaptabilidade das condições de trabalho. São estabelecidos arranjos na composição curricular com vistas a atrelar os conteúdos programáticos ao mercado de trabalho flexível; o exemplo disso é a substituição de disciplinas como introdução à filosofia, metodologia científica e sociologia por, respectivamente, "desenvolvimento pessoal", "responsabilidade social" e “cidadania e interculturalismo". Mais do que a mudança de conteúdos é a perspectiva da interdisciplinaridade imposta por essa lógica, que não exige uma formação específica para atender a essas demandas.

Ainda no que tange à reestruturação curricular, a Portaria $n^{\circ} 4059$ de 10 de dezembro de 2004 contribui com a flexibilização dos cursos e seu ajuste financeiro à medida que possibilita que as IES ofertem disciplinas na modalidade semipresencial, desde que não ultrapassem $20 \%$ da carga horária total do curso. Destaque para o $\S 1^{\circ}$ do Art. $1^{\text {o: }}$ :

Para fins desta Portaria, caracteriza-se a modalidade semipresencial como quaisquer atividades didáticas, módulos ou unidades de ensinoaprendizagem centrados na autoaprendizagem e com a mediação de recursos didáticos organizados em diferentes suportes de informação que utilizem tecnologias de comunicação remota. 
O que ocorreu na prática é que em algumas IES, os professores deixaram de lecionar presencialmente e parte de sua carga horária é cumprida pelos alunos mediante cursos via online, chamado em algumas instituições de ambiente virtual de aprendizagem (AVA).

A instabilidade do emprego e as cobranças feitas pelas IES pressionam o docente que ministra aulas presencialmente de diversas maneiras. Podemos exemplificar um conjunto de exigências a que esses profissionais têm que responder.

A preparação das aulas e a correção das atividades ocorrem fora do espaço escolar, sem remuneração. A organização do cronograma de todas as atividades docentes durante o semestre e preparação das atividades avaliativas, em muitos casos, é submetida ao crivo da coordenação pedagógica. Além disso, o docente deve alimentar e manter atualizada a caderneta eletrônica, participar de reuniões com a coordenação dos cursos, o que via de regra não é remunerado; como também, é “convidado" pela direção a participar de eventos externos da instituição, literalmente na condição de "colaborador"; ; ademais é exigido a participação em cursos de capacitação externa e interna para compor seu currículo e deixá-lo atualizado. Em diversos momentos atua como garoto-propaganda da instituição na captação de novos alunos, participa "voluntariamente" nas comissões internas que recebem comitivas do MEC para abertura, reconhecimento e recredenciamento de cursos; isso tudo somado ao trabalho excessivo pelo número de aulas em diversas disciplinas e número elevado de alunos.

Na nossa experiência como docente nas IES privadas por oito anos, constatamos uma realidade peculiar no que diz respeito à contratação de professores. Diferentemente das IES públicas que selecionam professores mediante concurso público, as instituições particulares seguem ditames de seleção como qualquer outro emprego, além de existir uma tendência de indicação por parte do quadro docente ou do dirigente da instituição. Como não existe uma legislação específica que normatiza a docência em instituição superior privada, muitas delas contratam profissionais com especialização lato sensu e os docentes se veem como professores, sem nenhuma passagem pela licenciatura ou qualquer outra formação do gênero, atuando, sobretudo, nos cursos da área de ciências sociais aplicada. Esse trabalhador divide seu tempo entre a docência e sua atividade principal:

Outro aspecto a se destacar é que a docência em instituições privadas, não raramente, assume uma posição secundária, de modo que, em muitos momentos, o professor se torna um "aulista", um "tarefeiro", para uma clientela "selecionada" através de exames de admissão de caráter duvidoso. $\mathrm{Na}$ realidade, as condições precárias de trabalho não favorecem o cultivo de 
requisitos essenciais para um envolvimento adequado com a docência, como a preparação criteriosa de aulas e o desenvolvimento de projetos de pesquisa e de extensão. Nesse último caso, o envolvimento costuma não acontecer, tanto pela tendência de aumento da carga horária no ensino, pois as horas pagas são as dedicadas ao tempo de trabalho em sala de aula, como pelas alternâncias entre contratação e dispensa, conforme as necessidades do currículo (disciplinas por semestre). Essa situação inviabiliza a realização de um trabalho acadêmico digno (BESSA, 2006, p. 13).

O estudo sobre docência em instituição de ensino privado desenvolvido por AMORIM (2009) corrobora o caráter tarefeiro do docente, circunscrito numa divisão do trabalho bem pontual. A natureza do trabalho docente na instituição não é questionada pelo trabalhador; a finalidade da instituição é obter cada vez mais alunos, desenvolver uma atividade-meio cuja meta é o diploma do consumidor. Ao entrevistar os professores, Amorim ouviu deles que o processo educativo no qual estavam inseridos, relacionava-se muito mais ao ato de transmitir informações do que construir estratégias para que os docentes produzam conhecimentos. Conclui o autor, pontuando que o docente é um trabalhador como qualquer outro, seu processo de trabalho está cindido e simplificando pelas variadas formas de racionalização da produção, se tornando repetitivo, monótono e desestimulante para quem o executa.

Apesar de o professor ter consciência dos pontos negativos da universidade privada e saber que isso afeta as suas práticas de trabalho, ele não sabe como isso acontece de maneira objetiva. O professor não tem tempo para muitas reflexões, carrega no dia a dia as suas frustrações. Ele ensina na universidade, sem ter formação adequada para isso, para pessoas que não têm formação adequada para receber os ensinamentos relativos ao terceiro grau, não tem incentivo para completar a sua formação, não faz pesquisa, enfim, tem o seu trabalho precarizado de todas as formas (AMORIM, 2009, p. 18).

A problemática da precarização e da desqualificação docente faz parte do debate acerca do conceito de proletarização dos trabalhadores da educação. Embora esteja claro em nossas reflexões que o docente que atua nas IES privadas é um proletário, essa análise conceitual permite-nos compreender as vicissitudes de um processo de trabalho que está em constante transformação, cada vez mais cerceando a autonomia dessa camada de trabalhadores. Ao revisitar tais conceitos, temos em vista analisar de que maneira o fenômeno da precarização tem afetado o trabalho docente na atualidade.

Ao discutir o caráter ambíguo da docência, Enguita (1991) analisa que os docentes transitam entre a profissionalização - que diz respeito a uma posição social e ocupacional, que conota certa autonomia no processo de trabalho - e a proletarização, compreendida como o 
"processo pelo qual um grupo de trabalhadores perde (...) o controle sobre seus meios de produção, o objetivo de seu trabalho e a organização de sua atividade" (op. cit., p. 46). Considerar o trabalho de um docente do ensino superior como precarizado e desqualificado poderia soar estranho aos ouvidos há algumas décadas, ainda mais se pensarmos no prestígio social que a categoria possuía (e em certa medida ainda possui). No entanto, é a forma concreta que o trabalho assume que determinará a real condição de membro dessa ou daquela camada ocupacional, ou em última instância, dessa ou daquela classe social.

O que faz com que um grupo ocupacional vá parar nas fileiras privilegiadas dos profissionais ou nas desfavorecidas da classe operária não é a natureza dos bens ou serviços oferecem, nem a maior ou menor complexidade do processo global de sua produção, mas a possibilidade de decompor este último através da divisão do trabalho e da mecanização - que está, sim, determinada em parte por sua natureza intrínseca, a do processo -, o afã das empresas capitalistas ou públicas por fazê-lo - que depende da amplitude de seu mercado real ou potencial - e a força relativa destas e daquele, isto é, de empregadores e empregados reais ou potenciais (op. cit., p. 42-3)

Proletário, segundo o autor, é o sujeito que se vê obrigado a vender sua força de trabalho e gerar um sobrevalor ao capitalista maior do que o salário que recebe; o proletário gera mais-valia no processo de acumulação e para que isso ocorra com o máximo de eficiência, o comprador da força de trabalho emprega todos os meios disponíveis para controlar o processo de trabalho. Os docentes não estão isentos dessa tendência à proletarização das profissões, embora esses processos não se efetivem da mesma forma ou com os mesmos resultados em todas as categorias. Ressaltamos mais uma vez que os docentes das IES privadas são proletários, mas os elementos da desqualificação profissional atingem também os trabalhadores das instituições públicas, guardadas as especificidades de cada esfera. A divisão do trabalho e sua distinção entre concepção e execução das tarefas adentram aos portões das instituições de ensino no momento em que a direção organiza e padroniza os programas de curso, as ementas dos componentes curriculares e veladamente incentiva os professores a utilizarem recursos em sala de aula, que não sejam exclusivamente pincel e quadro. Dessa forma, afirma o autor que o docente "tem perdido progressivamente a capacidade de decidir qual será o resultado de seu trabalho, pois este já lhe chega previamente estabelecido em forma de disciplinas, horários, programas, normas de avaliação, etc." (op. cit., p. 48). A sensível perda do controle docente sobre o processo de trabalho e por outro 
lado, as peculiaridades de uma atividade que não é substituída integralmente pelas máquinas, constituem o cenário da ambivalência:

Como consequência, a categoria dos docentes move-se mais ou menos em um lugar intermediário e contraditório entre os dois polos da organização do trabalho e da posição do trabalhador, isto é, no lugar das semiprofissões. Os docentes estão submetidos à autoridade das organizações burocráticas, sejam públicas ou privadas, recebem salários que podem caracterizar-se como baixos e perderam praticamente toda capacidade de determinar os fins de seu trabalho. Não obstante, seguem desempenhando algumas tarefas de alta qualificação - em comparação com o conjunto dos trabalhadores assalariados (op. cit., p. 50).

Pucci, Oliveira e Sguissardi (1991) também destacam a questão da proletarização, autonomia e desqualificação profissional docente, afirmando que de um lado os professores são alienados no processo de trabalho, já que poucos participam das diretrizes escolares e das políticas educacionais, além do fato da burocracia e do autoritarismo prevalecer em suas relações de trabalho, mas ao mesmo tempo têm certa autonomia na sala de aula, mediante a condução de suas atividades junto ao alunado. Sobre a proximidade e o distanciamento do trabalho docente em relação ao trabalho fabril, indicam os autores que as condições objetivas de trabalho, centradas na desqualificação, colocam os docentes muito próximos dos operários, além de proporcionar "uma aproximação real do professor com os proletários enquanto classe, através de seu processo de organização e de luta" (op. cit., p. 91). Mas, apontam também as diferenças entre eles e algumas peculiaridades:

As escolas são ruins, mas as fábricas e os escritórios são muito piores: numerosos direitos que podem ser exercidos no local de estudo não podem sê-lo no local de trabalho; as relações de um aluno com seu professor costumam ser bastante mais livres que as de um operário com seu capataz ou de um empregado de escritório com seu chefe; a distribuição de recompensa é mais justa e objetiva nas escolas que nas empresas; as sansões são mais graves e se dão com mais frequência no trabalho que no ensino; o trabalho produtivo da maioria das pessoas é mais duro e menos atrativo do que foi seu trabalho escolar (ENGUITA apud PUCCI et. all., op. cit., p. 98).

Baseado na condição de proletário e considerando sua posição na esfera da acumulação próxima ao proletário fabril, questionamos a consciência de classe do docente e sua visão de mundo acerca da exploração a qual está submetido. Como apontaram os estudos de Pucci, Oliveira e Sguissardi (1991), ocorre um reconhecimento da condição de luta trabalhista empenhada pelos professores da rede básica de ensino, que se organizaram em 
estruturas pela elaboração de pautas reivindicatórias que permeiam seu trabalho, e gradativamente formaram as associações e os sindicatos desses profissionais. No caso dos professores das IES privadas, o mesmo processo de combate à precarização não ocorreu:

Essa situação não é reconhecida nos processos de organização do professor das IES privadas. A principal contradição reside no fato de que este não tem espaço legítimo de reivindicação; como professor do ensino superior, ele poderia estar próximo das entidades docentes estruturadas no âmbito da universidade pública. Nesse nível, a universidade de elite apresenta-se como melhor porque também seu corpo docente assim pode se apresentar; elite porque articula ensino e pesquisa, porque tem reconhecimento acadêmico e profissional, porque está salvaguardada por um plano de carreira mais consistente, porque pode dispor de verbas de fomento à pesquisa, porque conta com tecnologia mais sofisticada, porque não se submete os ditames da iniciativa privada, entre outros fatores. Esse conjunto de "privilégios", se comparado com as possibilidades dos professores do ensino superior de massa, coloca os docentes das universidades públicas em situação diametralmente oposta aos professores das instituições privadas, pois suas preocupações são outras e em suas pautas de reivindicações não constam nada que possa ser objeto de luta comum (CAMARGO, 2012, p. 83-4).

A literatura consultada (CAMARGO, 2012; SIQUEIRA, 2006; DIAS, 2006) nos indica que os referidos docentes estão associados aos sindicatos dos professores da rede particular de ensino: Sindicato dos Professores (SINPRO) de seus respectivos estados. No entanto, essa entidade de classe representa todos os níveis de escolaridade, de modo que os profissionais do ensino superior não têm um espaço específico e apropriado para debater suas pautas. De maneira geral, as relações com o sindicato são formais e de pouca representatividade, principalmente por conta da força dos professores do ensino fundamental e médio ${ }^{\text {ii }}$. Camargo (2012) aponta que os docentes ficam isolados no que tange às reflexões de sua atividade prática, podem se sentir acuados pelos donos das mantenedoras em participar efetivamente das atividades sindicais, além de não contar com o apoio declarado de associações de vanguarda. Se não bastasse, esse docente "sofre algum preconceito por participar, como trabalhador, de um projeto considerado de 'segunda linha' perante a estrutura universitária" (op. cit., p. 84).

Sem apoio sindical, com contratos e remuneração baseado na hora-aula, lecionando em mais de uma instituição para compor um salário razoável, pouca ou nenhuma relação com extensão ou pesquisa, o docente-auleiro ainda se submete a uma nova face da precarização, no qual a sua produtividade é verificada e contabilizada à luz da flexibilidade acadêmica. 


\section{Face da precarização do trabalho docente: a questão do produtivismo}

Ao refletir sobre a realidade do ensino superior, Bosi (2007) critica a dinâmica produtivista que impõe a lógica fabril ao trabalho acadêmico, trazendo consequências nefastas para o desenvolvimento da ciência, além de submeter (mais ainda) o docente às exigências da lógica mercantil iii. O ideário de que o professor precisa ser "mais produtivo" diz respeito não só à quantidade de sua "produção" (aulas, orientações, publicações, projetos, patentes, etc.), que passa a ser mais importante que a qualidade da mesma, mas também tange à natureza das pesquisas financiadas, com o fito de potencializar "a capacidade de reprodução do capital, desenvolvendo uma razão instrumental que pode ser facilmente verificada no caráter dos editais divulgados" (op. cit., p. 1513). Após explicitar algumas novas atribuições do docente, dentre as quais o "empreendedorismo" que o leva à produção em série de cursos de pósgraduação lato sensu, o autor atenta para uma faceta do controle externo da produção acadêmica, que diz respeito à regulação desse trabalho:

O adensamento e a intensificação do trabalho são traduzidos em números
que estruturam as diversas avaliações ditas institucionais. Assim, do mesmo
modo que os cursos de graduação têm sido classificados e hierarquizados
desde o "Provão" (transmutado em SINAES), e os programas e cursos de
pós-graduação têm sido referenciados em conceitos de 3 a 7 , a produção
docente também tem sido esquartejada, mensurada, tipificada e classificada
por critérios quantitativos. Os artigos científicos são valorizados de acordo
com o periódico que o veicula, isto é, caso esteja indexado
internacionalmente ou pelo "Qualis/CAPES" (indexador nacional oficial que
classifica os periódicos em 9 níveis). Nesse "vale quanto pesa", o próprio
docente é "valorizado" pela inserção na pós-graduação, pelo número de
orientações, artigos e livros publicados e, principalmente, pela "bolsa
produtividade em pesquisa" que consegue por méritos próprios (op. cit., p.
1515-1516).

Se do ponto de vista das aparências o professor se vangloria do seu alto desempenho, em essência não percebe que a natureza e o ritmo do trabalho é definido e imposto pelos interesses do mercado ${ }^{\text {iv }}$. Cria-se um ambiente de competitividade constante na academia, revelando uma racionalidade individualista que interfere, não raro, na saúde física e mental dos profissionais.

Trein e Rodrigues (2011) também discutem sobre a precarização do trabalho docente com base no conceito de produtivismo implantado na Academia nos dias atuais. Os autores apontam, baseado no I capítulo d'O Capital, que "há um empuxo irresistível na conversão de todos os objetos e atividades úteis ao homem (sejam úteis ao estômago ou a fantasia, 
repetimos) em mercadoria". (Op. cit., p. 776). Mais adiante, se apoiam na reflexão que Marx empreende no capítulo XIII da mesma obra, "A maquinaria e a indústria moderna", ao mostrar o papel que a ciência e a tecnologia ocupam enquanto força produtiva, oportunizando uma maior produção possível num menor tempo de trabalho. A partir de então, apontam um duplo aspecto desse processo no âmbito do trabalho científico: em primeiro lugar, a ocorrência de uma desenfreada corrida dos pesquisadores para concorrer aos editais, se enquadrarem nos indicadores de produtividade e garantir a continuidade da produção científica, numa divisão do trabalho que se estende aos mestrandos e doutorandos; por outro lado, os pesquisadores criticam a postura governamental na defesa de uma "nova" teoria do capital humano, modelando uma ideologia que identifica a ciência como tecnologia ao produzir inovações, contribuindo para o desenvolvimento econômico e social. Para os autores, "o produtivismo é o fantasma-fetiche que assombra/seduz, com promessas e ameaças, a academia" (TREIN e RODRIGUES, 2011, p. 780).

Uma forma concreta que se apresenta como resultado desse fetiche é a demanda por publicação científica. Na lógica flexível essa demanda se constitui como um dos principais critérios para obtenção de financiamentos, bolsas e outros pleitos acadêmicos; entretanto, dado aos elementos do produtivismo elencados anteriormente, como o prazo curto das pesquisas, a quantificação do trabalho intelectual, etc., a comunidade universitária tem-se utilizado da fraude acadêmica, "diante da diferença entre o tempo necessário para a produção do conhecimento e a pressão para a apresentação dos resultados” (op. cit., p. 782). E mais adiante explanam os autores:

Castiel e Sanz-Valero (2007) questionam o fetichismo de que se reveste o artigo científico e advertem que se estima que metade dos trabalhos publicados na área das ciências sociais jamais será citada. Eles apontam que na área de saúde pública o aumento quantitativo de publicações não se refletiu em melhorias na saúde das populações. Para eles, faz-se urgentemente a retomada da discussão em torno das questões éticas que devem nortear o fazer científico, pois hoje há uma espécie de naturalização de diversos procedimentos fraudulentos que são vistos como uma forma de gerenciamento do currículo. Eles citam, dentre outros, procedimentos como plágio, plágio de si mesmo, aumento de autores por artigo, troca de favores pela citação de colegas que retribuem com citações em seus textos, uso de referências sem consulta aos textos citados, fatiamento dos resultados de pesquisa de forma que rendam mais artigos e trabalhos apresentados em congressos. A lista de possibilidades de burlas (ou de gerenciamento de currículo) parece não ter fim (TREIN e RODRIGUES, p. 783). 
Esse fenômeno demonstra não apenas a mercantilização da educação, mas todo um esquema de controle do trabalho docente por parte das agências estatais como a Coordenação de Aperfeiçoamento de Pessoal de Nível Superior (CAPES) e Conselho Nacional de Desenvolvimento Científico e Tecnológico (CNPq). Guimarães; Monte; Farias (2013) apresentam essa lógica produtivista e nos indicam dois instrumentos de controle bem conhecidos pela comunidade acadêmica. O primeiro é a Coleta CAPES, definido como

(...) um sistema criado para coletar informações sobre os programas e cursos de Pós-Graduação no Brasil, é através destes dados coletados que as comissões de área avaliam e definem o conceito dos cursos, classificando, ranqueando e definindo quais poderão continuar oferecendo a capacitação. (Op. cit., p. $43, \operatorname{nota}^{\circ} 2$ )

O segundo é a implantação pelo CNPq, em 1999, do Currículo de Plataforma Lattes, utilizado como padrão para o registro das atividades desenvolvidas pelos membros da comunidade científica brasileira. "A centralização dos currículos, (...) exige dos profissionais uma atualização periódica e uma produção constante para garantir uma boa pontuação no "mercado acadêmico"” (op. cit., p. 39). Os autores ressaltam a relação dialética entre prazer e sofrimento no trabalho, uma vez que ocorre uma espécie de ditadura do relógio, exigindo cumprimento de prazos, alcance de metas, incrementando a produtividade do seu trabalho e provocando a internalização desse fato como sendo algo natural.

Num estudo sobre a universidade no âmbito da reforma neoliberal, Pinheiro (2004) aborda o produtivismo na medida em que a quantidade das pesquisas é mais importante que a qualidade das mesmas; seguindo esse raciocínio, cita o professor Dalmo Dallari: "Não se procura saber a importância do tema pesquisado, não se faz qualquer diferença entre uma pesquisa e outra, porque todas as pesquisas foram jogadas na vala comum da quantificação" (op. cit., p. 284). Sobre a incorporação do ethos empresarial pelas universidades, Pinheiro critica as práticas acadêmicas que valorizam o efêmero, o fragmentado e o pragmatismo utilitarista; sobre a dinâmica da produção intelectual desenfreada, explica o autor:

$\mathrm{Na}$ esfera própria do pensar, da reflexão crítica, da elaboração de ideias e conhecimentos há determinados tensionamentos, conflitos, contradições e até mesmo incompatibilidades entre quantidade e qualidade, fundamentalmente quando se configura o domínio ou predominância da produtividade como ideia-força. Aí, a quantidade tende a se contrapor à qualidade histórica e a produtividade, à reflexão consistente ou à crítica fundamentada. $O$ tempo requerido para a elaboração de novos conhecimentos, realização de investigações ou estudos teóricos e práticos, maturação do conhecimento sob o crivo crítico, diálogo entre diferentes 
teorias e experiências e imprescindíveis discussões públicas se estrutura no mundo das incertezas, contrapondo-se à ideia de produtividade e eficiência (mais, em menos tempo, com menor custo) e às normatizações do trabalho empresarial (op. cit., p. 285).

O autor destaca o quão próximo está o trabalho acadêmico do fetiche da mercadoria, apontando ainda que a pesquisa, o trabalho de investigação e o senso crítico passam a ser o meio, e a quantificação de publicações em revistas indexadas o fim em si mesmo. A ciência se transforma em força produtiva, e se atrela cada vez mais às vicissitudes do mercado.

\section{4. Últimas considerações}

Percebemos na presente digressão, dentre outras discussões, que as mudanças na organização do trabalho centradas na acumulação flexível demanda uma reconfiguração do perfil docente; a exploração do trabalho pelo capital, pressupõe fenômenos como a desqualificação, a precarização e a intensificação do trabalho em todas as esferas produtivas, e o setor de serviços no qual está inserido a mercadoria-educação das IES privadas não é diferente. Por trás das faixas e outdoors das faculdades particulares que são iluminados pelas ideias de oportunidade, ascensão social, empregabilidade, sucesso profissional, etc., está obscurecida a realidade de um professor universitário que é visto pela escola-empresa como uma coisa (mercadoria) que deve gerar lucro no final do processo produtivo. No entanto, entendemos que a realidade social é dinâmica e suas transformações ocorrem de forma veloz, difícil de ser capturada na sua totalidade pela teoria social: torna-se imperioso investigarmos o chão da escola, o cotidiano de uma IES, para que, à luz do materialismo histórico, possamos estabelecer os nexos da sociabilidade capitalista.

\section{Referências}

AMORIM, Eliana de Paula Silva. A docência na universidade privada: entre o trabalho e o emprego. In: Revista Trabalho \& Educação. Vol. 18, nº 2, mai/ago 2009.

BESSA, Denise. Trabalho docente no ensino superior sob o contexto das relações sociais capitalistas. In: Reforma universitária: dimensões e perspectivas. Campinas: Alínea, 2006.

BOSI, Antônio de Pádua. A precarização do trabalho docente nas instituições de ensino superior do Brasil nesses últimos 25 anos. In: Revista Educação e Sociedade. Campinas, vol. 28, n. 101, p. 1503-1523, set./dez. 2007. 
BRASIL. PORTARIA No 4.059, DE 10 DE DEZEMBRO DE 2004 (DOU de 13/12/2004, Seção $1, \quad$ p. $\quad 34)$. $\quad$ Disponível em http://portal.mec.gov.br/sesu/arquivos/pdf/nova/acs_portaria4059.pdf. Acesso em 15/02/2016.

BRUNO, Lucia. Educação e desenvolvimento econômico no Brasil. In: Revista Brasileira de Educação. v. 16, n. 48, set.-dez. 2011.

CAMARGO, Luís Fernando de Freitas. A condição do professor do ensino superior privado: características estruturais da atividade docente e os processos de transformação nas relações de trabalho. Tese de Doutorado - Programa de Pós-Graduação em Educação - Universidade de São Paulo. São Paulo: s.n., 2012.

DIAS, Adelino José de Carvalho. O ensino superior privado em Uberlândia: precarização do trabalho docente. Dissertação de Mestrado - Programa de Pós-Graduação em Educação Universidade Federal de Uberlândia. 2006.

ENGUITA, Mariano Fernández. Ambiguidade da docência: entre o profissionalismo e a proletarização. In: Revista Teoria \& Educação, v. 4, p. 41-61, 1991.

GUIMARÃES, André Rodrigues; MONTE, Emerson Duarte; FARIAS, Laurimar de Matos. O trabalho docente na expansão da educação superior brasileira: entre o produtivismo acadêmico, a intensificação e a precarização do trabalho. In: Revista Universidade e Sociedade, $\mathrm{n}^{\circ}$ 52, Andes-SN, p. 34-45, julho de 2013. Disponível em http://apur.org.br/wpcontent/uploads/2013/10/imp-pub-1716063987.pdf. Acesso em 11/09/2014.

PINHEIRO, Luiz Humberto. Universidade dilacerada: tragédia ou revolta? Tempo de reforma neoliberal. Salvador: LU Pinheiro, 2004.

PUCCI, Bruno; OLIVEIRA, Newton Ramos de; SGUISSARDI, Valdemar. O processo de proletarização dos trabalhadores em educação. In: Revista Teoria \& Educação, v. 4, p. 91108, 1991.

SIQUEIRA, Tania Cristina Alves de. O trabalho docente nas instituições de ensino superior privado em Brasília. Tese de doutorado. Universidade de Brasília. Brasília, dezembro de 2006.

TREIN, Eunice; RODRIGUES, José. O mal-estar na Academia: produtivismo científico, o fetichismo do conhecimento-mercadoria. In: Revista Brasileira de Educação. V. 16, n. 48, set.-dez. 2011. 


\title{
Notas
}

\begin{abstract}
${ }^{i}$ Destacamos entre aspas esse conceito, pois se refere a um novo jargão utilizado nas IES privadas que não ocorre por acaso: "É extremamente usual palavras do campo empresarial, hoje fazerem parte dos planos e projetos pedagógicos, como: produtividade, eficiência, gerência, clientes, gestão por metas, etc. Todo esse vocabulário é apresentado dentro de uma rede ideológica tecida para a reprodução do capitalismo flexível, afetando a escola, a universidade, seus alunos e docentes" (Bessa, 2006, p. 6-7).

ii Transcrevemos a seguir o depoimento de um docente capturando esse olhar sobre o sindicato, presente na pesquisa de Siqueira (2006, p. 155): "A relação que nós professores temos com esses sindicatos é simplesmente quando no início do ano temos que pagar aquela taxa, e também no período de maio, data base para a negociação de aumento, então a gente fica sempre na expectativa de que o sindicato irá conseguir".

iii Ressaltamos que esse fenômeno está presente não apenas nas IES particulares, mas principalmente nas instituições públicas de ensino superior. Se destacamos esse elemento, é porque afeta o trabalho docente como um todo, sem possibilidades de isolar a esfera pública de um lado e a esfera particular de outro.

iv "Essa cultura da produtividade - fator da ressocialização do docente no espaço acadêmico - é transferida para os alunos da graduação e da pós-graduação que passam a receber a pressão para que sejam produtivos sob quaisquer condições. A ponta de iceberg foi vista pela primeira vez quando os prazos para conclusão do mestrado e do doutorado (bem como os prazos das bolsas para esses cursos) sofreram seguidas reduções. As bolsas para o mestrado, por exemplo, tiveram redução de 3 para 2 anos e meio, no início da década de 1990, e de 2 anos e meio para 2 anos, no final dessa mesma década. Nessa nova ossatura institucional, os mestrandos e doutorandos quase sempre recebem pressão de seus orientadores e dos programas (que pleiteiam sempre a melhor pontuação na CAPES) para cumprirem esses prazos a despeito da qualidade final de seus trabalhos" (BOSI, 207, p. 1517).
\end{abstract}

\section{Sobre os autores}

Fábio Mansano de Mello. Mestre em Ciências Sociais pela Universidade Estadual de Londrina (UEL); Professor de Sociologia da Universidade Estadual do Sudoeste da Bahia (UESB/Campus de Jequié); Doutorando do Programa de Pós graduação em Memória, Linguagem e Sociedade - UESB/Vitória da Conquista.

Ana Elizabeth Santos Alves. Pós-doutora em educação pela Unicamp; Mestre e Doutora em Educação pela Universidade Federal da Bahia, Professora Adjunta da Universidade Estadual da Bahia (UESB) e Docente do PPG Memória: Linguagem e Sociedade. 